\title{
ESPACIALIDADES E SOCIALIDADES DA EDUCAÇÃO AMBIENTAL ALÉM DOS MUROS DA ESCOLA
}

\author{
Maria Inês Gasparetto Higuchi ${ }^{1}$ \\ Paulo Sérgio Maroti ${ }^{2}$
}

Resumo: O texto apresentado se refere às reflexões produzidas no VII EPEA Encontro de Pesquisa em Educação Ambiental pelo Grupo de Pesquisa de EA em Contextos Não Escolares. A apropriação das espacialidades além dos muros da escola é, ainda, um impasse e desafio tanto para educadores quanto para produção de conhecimento científico acerca desses processos educativos e suas implicações. Distanciar-se do conforto do espaço escolar para entrar em territórios menos homogêneos com socialidades diversificadas exige um olhar cuidadoso. Os caminhos para a práxis cotidiana e a compreensão desses processos estão em construção, e, por isso, demandam reflexões compromissadas que envolvam a formação de educadores, metodologias e campos epistemológicos coerentes. As discussões do grupo incluíram esse mundo de espacialidades e socialidades distintas, pelos quais a Educação Ambiental deve trilhar e cumprir seu papel transformador e emancipatório.

Palavras-chave: Educação ambiental não formal. Processos educativos em contextos não escolares. Espacialidade da educação ambiental.

\section{SPATIALITIES AND SOCIALITIES OF THE ENVIRONMENTAL EDUCATION BEYOND THE SCHOOL'S WALLS}

Abstract: This text comes out with reflections produced in the EPEA VII - Meeting for Research in Environmental Education Research Group for Non School Contexts. The attachment of the spatiality beyond the school walls is still an impasse and challenge for educators and for researchers about these processes and their educational implications. In those spaces outside of the comfort of school boundaries one faces a huge array of socialities, which requires a careful and distinguished look. Paths to everyday praxis and a full comprehension of these processes are under construction, and therefore demand compromised reflections involving many different aspects such as the training of educators, methodologies and coherent epistemological fields. The group discussions included theses spatialities and distinct socialities for which the Environmental Education must walk and fulfill its transformative and emancipatory role.

Keywords: Non-formal environmental education. Educational processes in non-school contexts. Environmental education spatiality.

\footnotetext{
${ }^{1}$ Doutora em Antropologia Social, Pesquisadora titular do Instituto Nacional de Pesquisas da Amazônia INPA - Laboratório de Psicologia e Educação Ambiental; Manaus - AM; higuchi.mig@gmail.com.br

2 Professor Adjunto da Universidade Federal de Sergipe/Campus de Itabaiana - SE. pauloteo@uol.com.br
} 


\section{ESPACIALIDADES Y SOCIALIDADES DE LA EDUCACIÓN AMBIENTAL MÁS ALLÁ DE LAS PAREDES DE LA ESCUELA}

Resumen: El texto que se presenta se refiere a las reflexiones producidas en el EPEA VII - Encuentro de Investigación en Educación del Grupo de Investigación Ambiental de la EA en Contextos No Escolares. La apropiación de la espacialidad más allá de los muros de la escuela sigue siendo un callejón sin salida, y un desafío para los educadores y para la producción de conocimiento científico sobre estos procesos y sus implicaciones educativas. Distanciarse de la comodidad del espacio de la escuela para entrar en las zonas menos homogéneas, con socialidades diversificadas, requiere una mirada cuidadosa. Los caminos hacia la praxis cotidiana y la comprensión de estos procesos están en construcción, por lo que requieren reflexiones que implican la formación de los educadores, las metodologías y los campos epistemológicos coherentes. Las discusiones de los grupos incluyeron este mundo de las espacialidades y socialidades distintas para las que la educación ambiental debe caminar y cumplir su función transformadora y emancipadora.

Palabras clave: Educación ambiental no formal. Procesos educativos en contextos no escolares. Espacialidad de la educación ambiental.

\section{Para começar a conversa...}

Historicamente a Educação Ambiental (EA) tem ocorrido, quase que exclusivamente, no espaço escolar. Várias são as razões desse fato, mas se nos mantivermos no âmbito de sua concepção é possível perceber alguns indícios. Por um lado, ao ser entendida como uma atividade de educação adjetivada, seu espaço se conforma na delimitação da escola. Na escola as educações se juntam, ora como disciplinas, ora como atividades complementares, mas sempre subjugadas a um plano político pedagógico vigente. Nesse espaço as territorialidades são bastante definidas em termos de rotinas, conteúdos e agentes responsáveis nas atribuições delineadas. Entretanto, essa concepção vem sendo desconstruída, uma vez que dessa forma a EA se constitui como ação estreitada e fragmentada, contrariando as mais recentes reflexões que solicitam posturas emancipatórias expandidas, relativas ao modo de viver e agir nas mais diversas espacialidades.

Por outro lado, ainda nesse entendimento adjetivado, quando o polo ambiental se sobressai, apenas as questões relativas ao ambiente parecem ser tocadas e permitidas no território da EA. Nessa perspectiva, toda vez que os objetos natureza e ecologia são evocados, cabe com propriedade essa educação tipificada. Vários trabalhos nos mostram que, também nesse viés, a EA é incompleta e não menos equivocada do que aquela cuja centralidade obtusa requer o reconhecimento do objeto educação como sinônimo de ser e estar na escola.

Esse cenário, mesmo combatido, persiste no chão de fábrica. Não se pode ignorar que há um grande empenho de gestores, ambientalistas e educadores para reverter esse estreitamento territorial e conceitual (MELLO; TRAJBER, 2007). Tal empenho tem produzido um avanço significativo, porém ainda distante do ideal de aplicação. Há uma linha de sintonia em admitir que a EA não é uma educação em favor do meio ambiente, ao contrário, deve ser uma educação dirigida às pessoas no sentido 
de transformação da sociedade (SUÁREZ; MARCOTE, 2009), de modo a incluir uma mudança de valores e padrões sociais para uma cidadania plena (LOUREIRO, 2003; GUIMARÃES, 2007; REIGOTA, 2008). Essa transformação deve atingir não apenas a relação imediata com o entorno, mas requer mudanças no sistema econômico, na forma de gestão política e sociocultural de modo a permitir uma nova forma de agir, uma nova ética que implique numa melhora das relações sociais, considerando o respeito a tudo que está ao nosso redor e que chamamos de meio ambiente (LOUREIRO, 2004b 2004c; 2010; GUIMARÃES, 2004a; 2004b; CARVALHO, 2008; GONZALES-GAUDIANO; LORENZETTI; 2009; LAYRARGUES, 2010).

Entender, pois, a EA como uma plataforma de transformação social, nos possibilita transportarmos sua efetiva realização a qualquer espacialidade. Como plataforma, a EA se constitui num espaço democrático e emancipatório que permite estabelecer um programa de ação sobre o qual os indivíduos se encontram para traçar pontes de acesso para uma nova forma de agir no mundo. A plataforma permite o deslocamento suave e facilitador para novos espaços sem considera-los estanques. Dessa forma, os territórios se ampliam e as socialidades se diversificam, de tal forma como a vida é. Ao redimensionar o conceito de EA como plataforma, esta deve ocorrer sem delimitações de tempo, lugar ou agentes. Nesse sentido a EA não se restringe a um lugar específico, mas que está em qualquer um deles e interfaceia muitos domínios. Também, não se pode admitir que os tempos são momentos descontínuos, uma vez que, ao transitarmos por diferentes lugares, continuamos a fazer parte de um tempo linear e cíclico que nos envolve por inteiro. Por fim, somos uma mesma essência pessoal nos lugares e tempos que passamos, mesmo que transformados por essas vivências. A EA deve apreciar esse indivíduo como uma unidade continuamente transformada.

Esse entendimento tem o ônus da permanência e da emergência, nunca prescrito ou acabado, sempre solidário e reflexivo. Portanto, estruturas fixas e delimitações territoriais precisas não combinam com esse pensar e fazer da EA. O que une e transborda na EA é uma reorganização permanente de sentidos e de práticas, que, apesar de serem suscitados em planos sociais definidos, vislumbram horizontes diferenciados de um mesmo mundo. É certo que os limites da escola encerram mais homogeneidade do que diversidade, quando se refere ao cotidiano ali vivido. É de consenso que o espaço da escola unifica um fazer, enquanto que o além dos muros se dispersa em vários outros fazeres, não menos importantes, da sociedade (GUIMARÃES, 2007).

O Programa Nacional de Educação Ambiental (ProNEA), lançado em 1994 e revisto em 2004, aponta novos horizontes de compreensão do processo educativo. Fica claro, em suas proposições, que a genuína educação deve permitir o sentido da alteridade, isto é, o de compreender as especificidades dos grupos sociais e sua realidade ambiental. Esses aportes abrem possibilidades para problematizar socialidades que subjugam tanto as pessoas quanto o ambiente em cuja matriz sua existência é produzida. De forma concreta, o ato educativo trará mudanças das condições materiais e simbólicas na relação pessoa-ambiente (LOUREIRO, 2008).

O ProNEA reafirma, ainda, que os processos educativos de EA são elementos chaves para gestão ambiental nos mais diversos espaços da sociedade. Nesse sentido, ampliar a ação da plataforma de transformação social é inerente ao fazer da EA. No entanto, esses espaços requerem múltiplas abordagens educativas, tendo em vista a heterogeneidade de público e contextos socioculturais sobre os quais se edificam modos diferenciados da relação pessoa-ambiente. Pelo caráter universal e democrático da EA, 
cada espaço requer alternativas diferenciadas para promover o enfrentamento maduro dos problemas socioambientais brasileiros (LOUREIRO, 2008).

A EA, nos diversos contextos não escolares, seja com moradores de unidades de conservação, com servidores em instituições, com fiéis de igrejas, com residentes em áreas de risco, com sobreviventes de tragédias ambientais, com cidadãos sem moradia, com trabalhadores rurais e com participantes de movimentos sociais entre outros, vem se estabelecendo como uma atividade cada vez mais premente. Nesse sentido, cabe refletirmos como essa EA vem ocorrendo e o que mais se destaca nesses processos educativos? A que os educadores ambientais devem estar atentos? Que socialidades estão sendo reconhecidas e trabalhadas nessas espacialidades? Enfim, temos muito que pensar. Iniciamos esses questionamentos, problematizando realidades socioculturais em diferentes espaços e lugares.

\section{2. $O$ espaço das pessoas, das coisas e de tudo o mais}

O processo educativo de pensar modos de vivência que incluem, indistintamente, todos os organismos vivos e não vivos, produtos, serviços e paisagens exige, necessariamente, repensar e transformar nossa trajetória humana neste planeta. Nessa trajetória as vivências não ocorrem num vácuo histórico ou descontextualizado dos momentos sociais em espaços distintamente separados. Como nos diz Ingold (2011; 2012), o ser humano é um ser imerso no fluxo da vida que, entrelaçada pelos processos e movimentos dos materiais do corpo e da mente, forma sua própria história biológica e cultural como uma unidade. Nessa afirmação Ingold reafirma a condição de que o ambiente não é algo externo ao ser humano, mas uma dimensão dele junto com tudo mais que o constitui.

Complementando, com o risco de nos distanciarmos das premissas de Ingold, nos ocorre que, se por um lado, como humanos não existimos sem a dimensão ambiental (atmosfera, biosfera, geosfera, hidrosfera, criosfera), somos nós, os humanos, que damos sentido (valores, significados) ao ambiente (organismos diversos, recursos e serviços). Portanto, a existência desses aspectos são, em última instância, produtos socioculturais. Como ponto de partida desses sentidos, nós humanos, por meio de nossas ações, transformamos nosso entorno e construímos novos arranjos espaciais e produtos para satisfazer as necessidades criadas a partir da organização social de cada grupo em que nos inserimos. É a partir dessa complexidade de ser e estar no mundo que a plataforma de transformação social se estabelece para transcender. Tal projeto de emancipação humana deve estar associado ao projeto de cuidado do ambiente (MORIN; KERN, 2000; LOUREIRO, 2004a). Um não existe sem o outro. A dissociação implica na perpetuação dos modelos vigentes de dominação humana e degradação ambiental (BOFF, 1999).

Ao mergulharmos profundamente nos processos de EA em contextos não escolares, como espaços contíguos de um mesmo mundo, é imperativo que nos demos conta de desvelar as socialidades presentes neles, para, então, repensarmos e propor transformações. Ao estar em territórios estranhos, damo-nos conta de um universo de significados que estão subjacentes nas relações pessoa-ambiente. Algumas dessas relações se mostram aparentemente contrárias à preservação e cuidado socioambiental. Apresentamos alguns exemplos clássicos que podem servir como reflexão e pontos de referência a essa plataforma de transformação social que é almejada pela EA, porém nem sempre simples de compreender. 
Valter van Beek e Pieteke Banga (1992) trazem o exemplo dos Dogons na África e o conflito existente entre homens e mulheres sobre uma atividade, que nos termos da sociedade ocidental moderna, é considerada ambientalmente degradante. Os Dogons veem as árvores e os seres humanos como aspectos ontológicos inseparáveis, isto é, um é parte do outro. Os Dogons acreditam que as árvores se tornam seres humanos com o passar do tempo. Em termos práticos, as árvores e arbustos são a fonte de vida para os seres humanos e, ao serem consumidos e aproveitados para a reprodução humana, esses recursos se tornam, então, seres humanos. Quanto mais árvores forem cortadas e consumidas para a atividade humana, mais cedo aquelas árvores têm a possibilidade de se tornarem humanos.

Os Dogons, como relatado pelos autores, não aceitam o fato de ser agentes dessa transformação e reprodução. Para eles, as árvores são seres autotransformadores, agentes de sua própria transformação e, por isso, os humanos não têm o direito de intervir na reprodução da vegetação, seja pela agricultura ou reflorestamento, por exemplo. A tarefa dos humanos é encurtar o tempo dessa permanência como árvore para que esses seres cumpram sua trajetória. Para os ambientalistas essa prática é desastrosa, por razões óbvias, sob o ponto de vista ecológico. Vê-se aqui um conflito a ser enfrentado pelos ambientalistas: como chegar a uma noção concernente ao fato de a prática sociocultural centenária estar produzindo a desertificação que, fatalmente, poderá resultar na morte de todos? Como entender que os Dogons não percebem isso?

O estudo apresentado por Melissa Leach (1992) mostra o caso existente entre o povo Mende, de Serra Leoa. Para os Mende, o homem é vital para o desmatamento de áreas florestais em cujas clareiras suas mulheres vão fazer uma área de plantação e cultivo. O papel e práticas sociais do homem e da mulher são definidos, principalmente, por essa atividade de produção de clareiras e plantio. Essa prática, entretanto está ameaçada com a introdução do cultivo de arroz, cacau e café, que passou a existir a partir da identificação do avanço acelerado do desmatamento. Atualmente, as mulheres cuidam do plantio do arroz e não dependem mais do homem para essa atividade. E os homens fazem clareira na floresta (mesmo não sendo permitido) para não ser cultivada por ninguém. As relações marido e mulher foram profundamente afetadas a partir da introdução dessa prática agrícola, e os índices de separações, problemas familiares e miséria têm provocado um desequilíbrio entre esses povos. Como fica, para esses indivíduos, o entendimento de uma norma imposta a partir de um conhecimento baseado numa premissa ecocêntrica para trazer uma melhoria na qualidade de vida das pessoas, para as quais diz ser orientada?

Maurice Bloch (1995) nos fala sobre o povo Zafimariny, que mantém a tradição de cultura itinerante de milho e feijão. Esse grupo do oeste de Madagascar vive numa estreita faixa de floresta entre altas montanhas, numa altitude média de $1.400 \mathrm{~m}$, pois adoram ver o horizonte modificado por eles. Nessa área, o rápido desmatamento chamou a atenção de ambientalistas e autoridades. Para conter essa situação, os gestores impuseram um novo tipo de agricultura: o arroz irrigado nos vales. A partir disso, os Zafimariny se confrontam, agora, com duas paisagens diferentes: o gradual desaparecimento da floresta (a floresta primária está cada vez mais longe e rara) e os terraços montanhosos, antes intocados, e agora com o cultivo de arroz. Para eles, esse cenário ambiental é visto em termos étnicos. Ser Zafimaniry é viver literalmente na floresta para poder usá-la e transformá-la em clareiras para poder ver o horizonte distante. $\mathrm{Na}$ ausência da floresta, os Zafimanirys deixam também de existir, se tornam outro tipo de povo, os Betsileos, um povo que vive em terra sem árvores e faz sua 
existência nos campos de arroz. Portanto, para continuar sendo Zafimaniry é necessário continuar a buscar a vida nas poucas áreas florestais, para poder utilizá-las de forma a permitir sua existência como povo distinto, vivendo de uma prática extrativista. Assim, na concepção desse povo, a preocupação com o meio ambiente não significa não prejudicá-lo, mas, sim, como ser bem sucedido em deixar sua marca nele, permitir a visualização do horizonte existencial de seus descendentes. Ao coibir as práticas de uso intenso das áreas florestais, incute-se nesse povo a condenação étnica. Como manter o respeito a essa forma de pensar dos Zafimaniry e à preservação ecológica?

Não precisamos, no entanto ir tão longe para verificarmos práticas socioculturais distintas que acabam por informar formas específicas de relações ecológicas. No estudo de Higuchi (1999) a autora constatou que a população vizinha de uma área florestal urbana em Manaus/AM não se sentia à vontade em ter aquela floresta tão próxima de suas casas, pois a considerava ociosa e ameaçadora. Ociosa porque era vista apenas como um lugar de árvores e bichos, o que seria um disparate na visão daquelas pessoas, uma vez que havia tantas outras pessoas que precisavam desesperadamente de um lugar para moradia. No relato de uma moradora: Por que manter uma área verde na cidade, se a floresta Amazônica está logo aí? Tem um mundo de árvore, que não acaba mais aí no nosso interior. Por outro lado, a área de vegetação próxima às suas casas representava uma ameaça real e simbólica. Real no sentido de que lá, tendo animais silvestres, esses poderiam escapar e por em risco a segurança dos moradores (mesmo que nunca tenham visto animal feroz na área). Simbólica, por que nas representações locais, quem mora perto da floresta está longe da cidade e longe do progresso, perto do fim, no limite da civilidade. Nesse entendimento, quanto mais urbano, no sentido de construído, mais inserido no contexto de prestígio e desenvolvimento se enquadra uma pessoa e, portanto, hierarquicamente superior à outra que se distancia dessa escala de status social constituída na prática (SILVA, 2009).

Observamos, através desses exemplos, práticas e concepções que podem diferenciar e até contrariar as formas de pensar e agir dos educadores e formuladores de políticas públicas. Como transitar nessa linha tênue de diferenças com a proposta de uma nova postura que requer, muitas vezes, o abandono por completo de certos comportamentos e atitudes vigentes? Certamente não é fácil responder. Porém, algumas considerações são necessárias.

\section{O mundo que vivemos}

A natureza da correspondência e da coerência entre a dimensão social e a dimensão ambiental não é tão simples. Ao considerarmos a pessoa por meio de sua inserção num ambiente, não podemos considerar sua existência destituída de uma materialidade. Essa materialidade não é, unicamente, uma propriedade exterior, com suas formas e substâncias concretas (GIBSON, 1986), mas um conjunto de matrizes em cujo domínio as pessoas desenvolvem sua existência. A relação dos seres humanos e do ambiente se dá na essência social, na medida em que todos os grupos sociais produzem e desenvolvem um tipo de espaço que lhes é próprio por meio da produção de suas relações (BACHELARD, 1964; BLOCH, 1995; BOURDIEU, 1997; CARSTEN; HUGH-JONES, 1995; DAMATTA, 1985; HIRSCH, 1995; HIGUCHI, 1999; 2008; INGOLD, 1995; 2000; LÉVI-STRAUSS,1983). O ambiente é, pois, um aspecto indissociável das pessoas que vivem nele. As pessoas é que definem e tecem sua organização, material e simbólica. 
O ambiente não é uma entidade independente, que existe fora, em oposição ao dentro. O meio ambiente é um campo dinâmico que só existe por meio das relações que estabelecemos com ele. Vários autores defendem que a criação de um ambiente é a criação da própria pessoa (FISCHER, S/D; INGOLD, 1995). É nas relações que desvendamos esses valores e significados. Por isso, Fischer (S/D) nos leva a ter sempre em mente tanto a socialidade da estrutura espacial quanto a espacialidade das estruturas sociais. Em outras palavras, a forma como organizamos e cuidamos de nosso entorno é um aspecto de nossas relações sociais, que mantemos um com os outros, portanto não é mero apêndice pragmático no mundo que vivemos.

A proposta teórica de Fischer (S/D) põe em evidência a natureza das interações entre as pessoas e o seu meio. Ao analisarmos as pessoas, seja em pequenos ou grandes grupos, estamos, por sua vez, considerando o espaço por elas ocupado, apropriado, modificado e personalizado. Mas Fischer (s/d, p.10) coloca que "se o espaço é socializado, é-o, por um lado, em razão das condições ambientais que orientam e enquadram os comportamentos e, por outro, das formas de atividades e de relações que aí se produzem." Com essa afirmação, o autor nos apresenta o aspecto indissociável entre os elementos próprios da realidade externa ou biofísica e os elementos socioculturais. A análise psicossocial e cultural comporta, dessa maneira, o estudo das formas das matrizes de existência que as diversas sociedades deram ao ambiente para organizar sua vida social. Fischer (s/d) nos apresenta duas maneiras de considerar essa relação no ambiente: uma baseada numa abordagem funcional (a maneira como as pessoas utilizam um lugar) e a outra como experiência vivida (conjunto de significados que esse lugar possui baseado nas experiências cotidianas). Essas duas formas de conceber um ambiente permitem-nos verificar que a relação pessoa-ambiente se circunscreve, por um lado, pelos atributos materiais que estão em nosso entorno, e, por outro lado, pela forma como é vivido na intersubjetividade dos sentimentos e laços afetivos a respeito do espaço e do lugar (TUAN, 1980).

Ao analisarmos as múltiplas interdependências que fazem do ambiente um sistema ao mesmo tempo mediador e transitivo das nossas relações com a nossa condição, e de maneira mais ampla, com a coletividade, permite que se precise o elo que existe entre a dimensão física e aquilo que chamamos de dimensão social. Mas que relação existe, de fato, entre as socialidades e as espacialidades do mundo? Segundo Fischer (s/d) não podemos dizer que haja simplesmente uma relação simétrica entre estruturas sociais e estruturas espaciais. Há, portanto, uma interdependência mútua e dinâmica, a qual pressupõe um princípio de complexidade entre essas estruturas, onde os processos socioculturais, inevitavelmente, informam a dinâmica dessa relação. Justamente, são essas dimensões que o educador ambiental não pode desconsiderar. Alguns estudos apresentados para o GDP do VII EPEA exemplificam esses pressupostos teóricos.

Edileuza Queiroz (2013), em seu estudo, alerta que a implementação da EA nas UCs é fundamental, pois nesses lugares ocorre o contato direto com a natureza. A EA pode possibilitar uma nova dinâmica socioambiental, tendo em vista que esses territórios se configuram como espaços que representam uma das formas de (re)ordenamento territorial e socioambiental. Nesses espaços as relações socioambientais são historicamente constituídas e dinamicamente movidas por tensões e conflitos sociais. Os processos educativos são importantes medidas para integrar tanto as espacialidades quanto as socialidades ao desenvolvimento regional, a fim de fortalecer as interações sociais e a participação cidadã. Nesse sentido, a EA deve 
permear vários campos e especialidades, dentre eles o ecoturismo, uma modalidade de turismo adequada às UCs. Um exemplo dado pela autora acontece no Parque Natural Municipal de Nova Iguaçu, localizado na Baixada Fluminense/RJ, onde há um grande fluxo de visitantes. Nesse caso, a formação de jovens nesse fazer conjunto de ecoturismo e EA traz não apenas a apropriação do território, mas também atua como geração de renda local.

Maryane Saisse (2013) mostra, em sua pesquisa, o estado da arte da institucionalização da EA na gestão ambiental pública federal, no contexto de formação dos atores sociais presentes nessa espacialidade e a presença no aparelho de Estado dos diversos interesses e disputas do campo em 28 UCs federais. A autora constatou que as políticas que dividiram o IBAMA e, consequentemente, desarticularam a Coordenação de Educação Ambiental, foram cruciais na fragilização das ações educativas de viés crítico e participativo, que aconteciam naquelas UCs antes dessa medida administrativa. Para Saisse, estando as estruturas das UCs inteiramente enfraquecidas, principalmente na atuação da EA, tornaram-se mais vulneráveis, ao mesmo tempo em que seus instrumentos de gestão foram esvaziados de sentido político.

Hernandez e Rabinovici (2013) apresentam um estudo sobre a possibilidade de uma EA engajada, principalmente, na mudança de perfil do consumidor e dos hábitos de consumo entre vendedoras de uma empresa de cosméticos que propala ser uma empresa com perfil sustentável em suas publicidades, programas e projetos. A venda dos produtos se dá, exclusivamente, pelas chamadas consultoras que atuam de porta em porta. Estas têm contato direto com os consumidores e, por essa razão, as autoras se questionaram sobre o potencial de sensibilização e possibilidade de intervenção educativa das consultoras. O estudo constatou que essas consultoras não se apropriam dessa possibilidade educativa e do discurso socioambiental da empresa para a conscientização de seus clientes. Diante desses resultados, as autoras recomendam uma capacitação e formação com estratégias diferenciadas de educação para o ambiente, compatíveis com as atitudes de vender e educar.

Araújo, Santos e Nunes (2013) contribuem com um estudo realizado pelo Programa de EA desenvolvido pela Universidade Federal de Sergipe com comunidades costeiras de Sergipe e do litoral norte da Bahia no Programa de Educação Ambiental em Áreas Costeiras - PEAC. Este programa é um critério condicionante de licenciamento da produção de petróleo e gás pela PETROBRAS UO-SEAL. Nesse estudo as autoras se prontificam a refletir tanto sobre o significado dessa atividade para a formação profissional de educadores ambientais quanto sobre papel da universidade pública nesse âmbito. Segundo as autoras, o estudo mostrou que a universidade, em seu papel de angariar esforços e oportunizar a produção de conhecimentos socialmente relevantes, permitiu uma atuação eficaz na intervenção da realidade daquelas comunidades. $\mathrm{O}$ trabalho coletivo junto às comunidades asseguraram tanto a gestão quanto a participação nas decisões necessárias naqueles lugares. $\mathrm{O}$ conhecimento das socialidades ali inseridas e o contexto ambiental em que se produziam foram vitais para a ampliação do poder de enfrentamento de conflitos e problemas comuns.

O trabalho de Iared e Oliveira (2013) contribui nessa discussão, aprofundando a reflexão sobre o significado das diferentes estratégias, experiências e vivências na formação de valores estéticos e éticos no Cerrado. Nessa direção, o estudo nos convida a considerar a educação estética que tem seu centro no corpo e seus sentidos, como base para nos situarmos e compreendermos o mundo que vivemos. São essas vivências e percepções que forjam diferenciadas atuações e expressões do cotidiano, que ocorrem a 
partir da intersubjetividade e diálogo. Para as autoras, a relação intercorporal possibilita a criação de um novo sentido ambiental estético e ético, aspectos importantes para os processos da EA. Esse estudo corrobora com os trabalhos de Nordi (1994a, 1994b, 1995) que faz uma avaliação dos meios pelos quais os seres humanos respondem ao meio ambiente, investindo na apreciação estética e no contato corporal. O autor faz referência à socialidade presente na espacialidade dos manguezais da região nordeste, onde há claras diferenças de percepção da população em geral e dos catadores de caranguejo, cujo contato com o mangue é intenso (os catadores praticamente se enterram no mangue, que lhes dá o sustento diário).

O estudo de Maroti e Santos (2004), por outro lado, nos mostra o entendimento dos ciclos econômicos como modificadores das paisagens e que, geralmente, não ultrapassam mais que duas ou três gerações de moradores de um determinado local. Os autores trabalharam com registro da memória, utilizando-se de recursos de SIG (Sistema de Informações Geográficas), junto a antigos trabalhadores (agricultores) de uma região do interior de São Paulo, que, até a década de 1950, era famosa por sua pujança econômica devida às plantações de café. Essa área onde esses trabalhadores residiam e trabalharam (foco da pesquisa) era uma antiga fazenda de café, recentemente transformada em unidade de conservação (Estação Ecológica de Jataí, em Luiz Antônio/SP). Os resultados do trabalho demonstraram diferenças significativas de percepção e afeição sobre a área entre esses antigos trabalhadores e as gerações atuais, referente ao uso dos recursos do passado e no tempo atual. Para os estudantes, moradores das cidades da região, e os visitantes da estação ecológica, essa área é de relevante importância para a conservação (é um dos últimos remanescentes de cerrado da região). Esses atores atribuíram, ainda, um alto valor às suas paisagens preservadas, enquanto os antigos agricultores e moradores do entorno da unidade tendem a considerá-la negativamente como terra improdutiva. Isso se deve, possivelmente, pelas vivências históricas das gerações anteriores que construíram suas vidas a partir da exploração econômica daquelas terras. Observam-se, nesse cenário, as relações de familiaridade, afeição e patriotismo como aspectos cruciais na percepção do e sobre o ambiente.

Nesse sentido, o que visualizamos é um processo histórico de pessoas e grupos sociais inscritos numa biografia socioambiental específica. Sendo assim, um indivíduo inscreve, modifica e organiza sua própria vida no mundo que vive. A compreensão da relação no espaço como experiência vivida nos fornece indícios importantes, pois nos mostra que os lugares estão carregados de valores afetivos e cognitivos ligados às subjetividades constituídas historicamente. Podemos perceber, dessa forma, que existe uma correspondência multidimensional e complexa entre os elementos físicos do ambiente e os fatores psicossociais presentes nesse encontro vivido (TUAN,1983). Para compreender os modos de agir e pensar das pessoas com outras pessoas e com todos os demais elementos de seu entorno, é preciso entrar nesses mundos que flutuam e se concretizam em movimentos constantes.

\section{Para encurtar a longa conversa e adentrar no espaço da EA}

Os dilemas pedagógicos encontrados na EA nos contextos não escolares incluem, por um lado, a ineficácia de certos modelos que, embora defendendo uma postura que considere as especificidades socioambientais, acabam por adotar atividades e normas onde se repetem clichês puramente naturalistas e globalizantes. Por outro lado, 
no cotidiano do fazer convivemos com dilemas sobre o que seria mais producente incluir nesse processo e como isso deveria ocorrer, levando em consideração tanto os aspectos socioculturais específicos dos participantes quanto os aspectos ecológicos. Desconsiderar esses aspectos é negligenciar a realidade totalizante dos fenômenos existentes. É considerar de forma incompleta e reduzida um fenômeno complexo, com grandes chances de, ao invés de trazer benefícios aos participantes, introduzir-se conflitos irreparáveis. A pesquisa nos fornece base para elaborar processos educativos mais eficazes e eficientes.

Com esses pontos a refletir, nos parece cada vez mais claro que ao planejarmos qualquer intervenção educativa em contextos não escolares, esses aspectos sejam considerados como imprescindíveis e se tornem pontos de reflexão para que possamos melhor entender a relação pessoa-ambiente. Essa trajetória pode nos indicar caminhos que contribuam com os valores por todos defendidos, o da melhoria da qualidade de vida para todos num mundo mais solidário e justo.

Tanto a antropologia quanto a psicologia tem nos ajudado a apontar algumas predisposições de determinados comportamentos, e, de modo geral, os estudos apontam que muito do que fazemos tem a ver com o que pensamos. Suárez e Marcote (2009) apontam duas causas sobre essa discrepância entre a preocupação ambiental e a realização de ações sustentáveis. Quanto à primeira, os autores citam que há um grande número de programas educativos que trazem implícita a noção ambígua e dispersa do que seria ação sustentável. Cada programa tem uma forma de discutir e aprofundar o que considera ser importante para o tema ambiental. Apesar de terem implícitas ideologias distintas, de modo geral há uma linha que aproxima todas essas iniciativas, que tem como princípio a busca da formação de cidadãos bem informados e capacitados para tomar decisões a respeito: a) da necessidade de uso racional e conservação dos recursos naturais; b) da impossibilidade do crescimento ilimitado; c) do atendimento das necessidades sociais das gerações atuais e futuras sem considerar objetivos individuais e imediatos; d) da necessidade de respeito mútuo e fomento às relações solidárias e cooperativas entre pessoas de grupos sociais e culturais diferenciados.

A segunda causa, de acordo com Suárez e Marcote (2009) a EA deve seguir o que Sauvé (1994) propõe ao ensino propriamente dito: a) Saber fazer - tendo informações e conhecimentos acerca da complexidade das questões socioambientais; $b$ ) Saber ser - tendo estímulos para sensibilizar diante dos problemas socioambientais e d) Saber atuar - tendo uma formação de competências a partir da reflexão dos problemas e tomada de atitudes responsáveis e cooperativas em favor da sustentabilidade.

De acordo com Suárez e Marcote (2009) temos muito a caminhar em relação ao saber atuar, uma vez que, de modo geral, os programas de EA ainda se mantêm numa relação bastante passiva diante da efetiva ação responsável, gerando o que Orr (1992, p. 95) chamou de "lição de hipocrisia". Diante dessa falta de formação ativa para a ação, os educandos acabam fazendo coro no que Dunlap (1983, p. 95) denominou de "frustração da conscientização", onde o sujeito aprendiz se lamenta por desnudar certos fatos que gostaria de mantê-los distantes de sua consciência. Assim, os autores recomendam linhas de ação que contemplem, inicialmente, a compreensão do problema, seguindo-se a identificação de possíveis estratégias de ação e, finalmente, a capacitação para ações definitivas de sustentabilidade. Um exemplo disso pode ser observado nos trabalhos de Higuchi, Freitas e Higuchi (2013) sobre considerações socioambientais de unidades de conservação do estado do Amazonas, e Nascimento et al. (2013) sobre o aproveitamento de madeira caída naturalmente na Reserva Extrativista Auati-Paraná, 
como catalisador para o estabelecimento de novos fazeres associados à tradição das comunidades para o manejo florestal madeireiro e desenvolvimento de tecnologias sociais inovadoras na Amazônia.

Diante das incertezas, instabilidades e diversidades nos fazeres da EA, um alento se dá ao reconhecer a necessidade de um conhecimento profundo da realidade contextual. A pesquisa interdisciplinar é um meio de evitar normatizações e rumos equivocados, permitindo a proposição de uma plataforma educativa que una as distâncias sem que se diluam as idiossincrasias que formam a beleza e concretude da vida neste planeta, seja no campo epistemológico, metodológico ou didático.

\section{Referências}

ARAÚJO, N.M.S.; SANTOS, J.S.; NUNES, C.A.S. Pesquisa e Educação Ambiental Não formal: contribuições da universidade pública. In: CAVALARI, R.F. et al. (Orgs.). Cadernos de Resumos e Programação do VII Encontro de Pesquisa em Educação Ambiental. Rio Claro/SP: UNESP, 2013. p.71.

BACHELARD. G. The Poetics of Place. Boston: Beacon Press, 1964.

BLOCH, M. People into Places: Zafimaniry Concepts of Clarity. In: HIRSH, E.; O'HANLON, M. (Eds.) The Anthropology of Landscape. Oxford: Clarendon Press, 1995. p.63-77.

BOFF, L. Saber Cuidar: ética humana - compaixão pela terra. Petrópolis: Vozes, 1999.

BOURDIEU, P. Outline of a Theory of Practice. Cambridge: University Press, 1997.

CARVALHO, I.C. de M. Educação ambiental: a formação do sujeito ecológico. São Paulo: Cortez, 2008.

CARSTEN, J.; HUGH-JONES, S. About the House: Lévi-Strauss and Beyond. Cambridge: University Press, 1995.

DAMATTA, R. Casa e Rua. Espaço, Cidadania, Mulher e Morte no Brasil. São Paulo: Brasiliense, 1985.

DUNLAP, R. E. International attitudes toward environment and development. In: BERGESEN, H.O.; PARMAN, G. (Eds.), Green Globe Yearbook of international cooperation in environment and development. Oxford: Oxford University Press, 1993.

FISCHER, G. Psicologia Social do Ambiente. Lisboa: Instituto Piaget, S/D.

GIBSON, J.J. The ecological approach to visual perception. Hillsdale: Lawrence Erlbaum, 1986.

GONZÁLEZ-GAUDIANO, E.; LORENZETTI, L. Investigação em educação ambiental na América Latina: mapeando tendências. Educação em Revista, Belo Horizonte, v.25, n.3, p.191-211, dez. 2009, 
GUIMARÃES, M. A formação de educadores ambientais. São Paulo: Papirus, 2004a.

GUIMARÃES, M.A Educação ambiental crítica. In.: LAYRARGUES, P.P. (Org.). Identidades da educação ambiental brasileira. Brasília: Ministério do Meio Ambiente, 2004b. p.25-34.

GUIMARÃES, M. Educação Ambiental: participação para além dos muros da escola. Em MELLO, S.S. de.; TRAJBER, R. (Orgs.). Vamos cuidar do Brasil: conceitos e práticas em educação ambiental na escola. Brasília: UNESCO, 2007. p.85-94.

HERNANDEZ, A.; RABINOVICI, A. O estímulo ao consumo consciente por meio da venda direta: o caso dos consultores natura de Sorocaba, SP. In: CAVALARI, R.F. et al. (Orgs.). Cadernos de Resumos e Programação do VII Encontro de Pesquisa em Educação Ambiental. Rio Claro/SP: UNESP, 2013. p.62.

HIGUCHI, M.I.G. Making Sense of dwelling place: a study among urban Amazonian children. Medio Ambiente y Comportamento Humano: An International Environmental Psychology Review, Madrid, v.9, n.1-2, p.149-170. 2008.

HIGUCHI, M.I.G. House, Street, Bairro and Mata: Ideas of Place and Space in an Urban Location in Brazil. 1999, P.372. Tese (Doutorado em Antropologia Social) Brunel University. Uxbridge, UK, 1999.

HIGUCHI, M.I.G.; FREITAS, C.C.; HIGUCHI, N. (Eds). Morar e Viver em Unidades de Conservação do Amazonas: considerações socioambientais para os planos de manejo. Manaus: Edição dos Autores, 2013. p. 268.

HIRSCH, E. Landscape: Between Place and Space. In: HIRSH, E.; O'HANLON, M. (Eds.) The Anthropology of Landscape. Oxford: Clarendon Press. 1995. p. 1-30.

IARED, V.G.; OLIVEIRA, H.T de. Formação de valores estéticos e éticos e o Cerrado. In: CAVALARI, R.F. et al. (Orgs.). Cadernos de Resumos e Programação do VII Encontro de Pesquisa em Educação Ambiental. Rio Claro/SP: UNESP, 2013. p.75.

INGOLD, T. Caminhando com dragões: em direção ao lado selvagem. In: SEIL, C.A.; CARVAlHO, I.C.M. (Orgs). Cultura, Percepção e Ambiente: diálogos com Tim Ingold. São Paulo: Terceiro Nome, 2012. p.15-30.

INGOLD, T. Being Alive: Essays on Movement, Knowledge and Description. Londres: Routledge, 2011.

INGOLD, T. The perception of the environment. Essays on livelihood, dwelling and skill. Routledge: London, 2000.

INGOLD, T. Building, Dwelling, Living. In: STRATHERN, M. (Ed.) Shifting Contexts. London: Routledge, 1995. 
LAYRARGUES, P.P. Educação para Gestão ambiental: a cidadania no enfrentamento político dos conflitos socioambientais. In: LOUREIRO C.F. B.; LAYRARGUES, P.P.; CASTRO, R.S. (Orgs.). Sociedade e Meio Ambiente: a educação Ambiental em Debate. $6^{\mathrm{a}}$ ed. São Paulo: Cortez, 2010.

LEACH, M. Women's Crops in Women's Spaces: Gender Relations in Mende Rice Farming. In: CROLL, E.; PARKING, D. (Eds.) Bush Base: Forest Farm. London: Routledge, 1992.p 76-96.

LÉVI-STRAUSS, C. The Way of the Masks. London: Jonathan Cape and Thirty Bedford Square, 1983.

LOUREIRO, C. F. B. Crítica ao teoricismo e ao praticismo na educação ambiental. In: NETO, A. C.; MACEDO FILHO, F. D.; BATISTA, M. S. S. (Orgs.). Educação Ambiental: caminhos traçados, debates políticos e práticas escolares. Brasília: Líber Livro Editora, 2010. p. 15-32.

LOUREIRO, C.F.B. Proposta Pedagógica. Salto para o Futuro: Educação Ambiental no Brasil, São Paulo - SP, Ano XVIII v. 1, p.3-12, 2008.

LOUREIRO, C.F.B. Ambientalismo e lutas sociais no Brasil. Revista Libertas, Juiz de Fora - MG, v.II, n.3, jan/jun., 2004a.

LOUREIRO, C.F.B. Educação ambiental transformadora. In: LAYRARGUES, P. P. (Org.). Identidades da educação ambiental brasileira. Brasília: Ministério do Meio Ambiente, 2004b. p.65-86.

LOUREIRO, C.F.B. Educar, participar e transformar em educação ambiental. Revista Brasileira de Educação Ambiental, Brasília, n.0, p.13-20, 2004c.

LOUREIRO, C.F.B. Emancipación, Complejidad y método histórico dialétictico: repensar las tendencias en educación ambiental. Tópicos en Educación Ambiental, v.5, n.13, p.21-30, 2003.

MAROTI, P.S.; SANTOS, J.E. A percepção ambiental de antigos trabalhadores da Fazenda Jatahy (Região de Ribeirão Preto, atual Estação Ecológica de Jataí): Mudanças topofílicas ao longo do tempo provocadas por diferentes ciclos econômicos. OLAM Ciência \&Tecnologia, RioClaro, v.4, n. 1, p.182-200, Abr., 2004.

MELLO, S.S. de. TRAJBER, R. Vamos cuidar do Brasil: conceitos e práticas em educação ambiental na escola. Brasília: UNESCO, 2007. p.248.

MORIN, E.; KERN, A.B. Terra Pátria. Porto Alegre: Sulina, 2000. 
NASCIMENTO, C.C.; MONTEIRO DE PAULA, E.V.C.; ARAÚJO, D.; HIGUCHI, N. A alternativa de uso social da madeira caída naturalmente na Resex Auati-Paraná. In: HIGUCHI, M.I.G.; FREITAS, C.C.; HIGUCHI, N. (Eds). Morar e Viver em Unidades de Conservação do Amazonas: considerações socioambientais para os planos de manejo. Manaus: Edição dos Autores, 2013. p.249-262.

NORDI, N. O processo de comercialização do caranguejo-uçá (Ucidescordatus) e seus reflexos nas atividades de coleta. Revista Nordestina de Biologia, João Pessoa - PB, v. 10, n.1, p. 39-45, 1995.

NORDI, N. A captura do caranguejo-uçá (Ucidescordatus) durante o evento reprodutivo da espécie: o ponto de vista dos caranguejeiros. Revista Nordestina de Biologia, João Pessoa - PB, v. 9, n.1, p.41-44, 1994a.

NORDI, N. A produção dos catadores do caranguejo-uçá (Ucidescordatus) da região de Várzea Nova, Paraíba. Revista Nordestina de Biologia, João Pessoa - PB, v.9, n.1, p.71-77, $1994 b$.

ORR, D. W. Ecological literacy: Education and the transition to a postmodern world. Albany: State University of New York Press, 1992.

QUEIROZ, E. Reflexões sobre possibilidades e desafios para a sustentabilidade socioambiental em unidades de conservação a partir de ações de educação ambiental. In: CAVALARI, R.F. et al. Cadernos de Resumos e Programação do VII Encontro de Pesquisa em Educação Ambiental. Rio Claro, SP: UNESP, 2013. p.34.

REIGOTA, M. Cidadania e Educação Ambiental. Psicologia \& Sociedade, Porto Alegre, v. 20, Ed. Especial, p.61-69. 2008.

SAISSE, M.V. Sentidos e práticas da Educação Ambiental no Brasil: as Unidades de Conservação como campo de disputa. In: CAVALARI, R.F. et al. Cadernos de Resumos e Programação do VII Encontro de Pesquisa em Educação Ambiental. Rio Claro, SP: UNESP, 2013. p.68.

SAUVÉ, L. Pour une éducacion relative à l' environnement. Montreal: Guérin. 1994.p 361.

SILVA, M.P.S.C. Aqui é melhor do que lá: representação Social da vida urbana das populações migrantes e seus impactos socioambientais em Manaus. Manaus: Editora da Universidade Federal do Amazonas, 2009.

SUÁREZ, P. Á.; MARCOTE, P. V. Una Propuesta educativa para la sostenibilidad. In: MIRA, R. G.; MARCOTE, P.V. (Orgs.). Sostenibilidad, Valores y cultura ambiental. $1^{\text {a }}$ ed. Madrid: Pirámide, 2009. p. 87-104.

TUAN, Y. Espaço e Lugar: a perspectiva da experiência. São Paulo: DIFEL, 1983. p. 250. 
TUAN, Y. Topofilia: um estudo da percepção, atitudes e valores do Meio Ambiente. São Paulo: Difel, 1980. p. 288.

VAN BEEK, W.E.A; BANGA, P.M. The Dogon and Their Trees. In: Croll, E.; Parkin, D. (Eds.) Bush Base: Forest Farm. London: Routledge, 1992. p. 57-75.

Artigo submetido em 09/12/2013

Artigo aprovado em 10/03/2014 